\title{
Information support of intellectual energy systems and its impact on ensuring balance reliability
}

\author{
Yuri Chukreyev ${ }^{1}$, Mikhail Chukreyev ${ }^{2}$ \\ ${ }^{1}$ Federal Research Center "Komi Scientific Center of the Ural Branch Russian Academy of Sciences", ISE and EPN, 167000, Russia \\ ${ }^{2}$ Federal Research Center "Komi Scientific Center of the Ural Branch Russian Academy of Sciences", ISE and EPN, 167000, Russia
}

\begin{abstract}
The is UPS of the impact of accounting for the energy supply of hydroelectric power plants on the means of ensuring the balance reliability of the UPS of Russia for the conditions of conducting commercial power take-offs are considered. The analysis of predicted and reported data on the generation of electricity at hydroelectric power stations and their impact on the rationale for backup tools.
\end{abstract}

\section{Introduction}

The state of the electricity industry has undergone significant changes since the end of last century. In organizational, technological and informational aspects. The transition to market relations in country has led to a significant reduction in energy consumption and capacity. In modern conditions, the task of substantiating values normative reserve of power (NRP) in planning development UES of Russia should be considered in a completely different plane. In the pre-perestroika period, there was a problem of power shortages and the task was to justify the inputs of generating facilities. Currently, there are significant excess capacity. The task is to justify the equipment commissioning (in the market terminology of power supply contract) and its dismantling. Its need is identified as a result implementation of competitive bids during a closed auction for commercial selection of capacity (CSC).

Development planning at all times is associated with the formation of power and electricity balances UES of the country. In accordance with the decree of the Russian Federation Government ${ }^{\mathrm{a}}$ since 2010, the noted balances are formed in the work "Scheme and Program for the Development UES for a 7-Year Period", annually carried out by JSC SO UPS and PJSC FGC UPS. Demand for power determines the expenditure side of the balance sheet and, in accordance with the Regulation on the procedure for determining this value $^{\mathrm{b}}$ (hereinafter

\footnotetext{
${ }^{a}$ Rules for the development and approval of schemes and programs for prospective development electric power industry, approved by Decree of the Russian Federation Government, October 17, 2009 No. 823.

$\mathrm{b}$ The Regulation on the procedure for determining the amount demand for long-term power take-off on a competitive basis in the wholesale market of electric energy (power) and the procedure for determining the planned coefficients of capacity reservation in the zones (groups of zones) of free flow of
}

Regulation No. 431), significantly affects the cost indicators of power during CSC. The amount demand for capacity includes three components: the projected maximum load, export / import of capacity and the value of NRP. The most difficult for consumers and suppliers of power and electricity to understand is the third component.

The magnitude of the NRP depends on many factors, including randomly determined. During CSC procedure, the amount of NRP in accordance with the aforementioned Regulation No. 431 is determined by the reservation coefficients approved by the RF Ministry of Energy for the allocated price zones of the electricity market. The numerical values of these coefficients are based on the materials of guidelines for designing the development energy systems, the latest edition of which was completed in the mid-90s of the last century and approved by the Russian Ministry of Energy only in 2003 [1]. It is obvious that this document requires its updating under modern realities.

The rationale for the NRP is based on the solution of the problem of assessing indicators of balance reliability (IBR) as applied to design scheme UES of Russia with the allocation territorial reliability zones in it [2]. The UES was the last in the development of 2003 guidelines. It is possible to split UES into smaller territorial zones. However, due to the complexity of the content, such fragmentation is advisable only in cases of significant influence of limited bandwidth between the allocated territorial zones. The enlargement of territorial zones to the UES level can also be justified by the fact that the procedure for conducting CSC currently focuses only on two price zones - the European part with Ural and Siberia.

It is known that in the CSC procedure the selection of the most efficient existing units of power plants is

electric energy (power), approved by the Order of the Russian Ministry of Energy from 09/07/2010 No. 431.

\footnotetext{
* Corresponding author: chukreev@iespn.komisc.ru
} 
carried out. It is not possible to take this aspect into account in models of ensuring balance reliability. It is clear that in the presence excess capacity of a hydroelectric power station in the economic aspect it is more attractive than a thermal one due to lower operational costs (lack of a fuel component). At the same time, their operating modes depend on weather conditions (dry years), and this aspect in modern conditions presence of excess capacity should be taken into account when substantiating backup means. Below are considered the issues of the possibility accounting for the energy supply of hydroelectric power plants during their joint work with thermal and nuclear power plants in the territorial zones UES of Russia.

\section{Methodological principles of accounting for restrictions on production of electricity at hydroelectric power plants when assessing indicators of balance reliability EPS}

When developing mathematical models for assessing the balance reliability indicators of multi-zone EPSs both in our country and abroad, approaches based on either analytical methods or statistical modeling methods are used. The latter approaches are most widespread due to the great potential to take into account various kinds of restrictions [2]. Regardless of the principles of managing the electric power industry (centralized, market), the methodology for solving the problem of assessing balance reliability indicators using statistical modeling methods is based on two interrelated stages:

- formation of load levels and random conditions of generating capacity caused by unplanned conclusions in emergency repairs of power plant equipment;

- assessments of the formed states with a view to ensuring the load of territorial zones.

The determination of balance reliability indicators is carried out sequentially for all time intervals during which the structure of generating capacities and the load remain unchanged [2-5]. The formation of random states for each territorial zone of the model of the calculation scheme UES of Russia is carried out by statistical modeling on the functions of the probabilities of reducing the generating capacities obtained by analytical methods due to unscheduled output of equipment for emergency repairs (regardless of the type of equipment) and load due to errors in predicting it, - caused mainly by temperature fluctuations. In order to evaluate the random state of the system formed in this way, due to many circumstances (information uncertainty, estimation of a large number of states, etc.), approaches based on the use of DC idealization are used [2, 5]. The summation indicators of balance reliability over all the allocated time intervals, taking into account the probabilities of their existence, allows us to determine their integral values.

To date, the models for evaluating balance reliability indicators of EPS have not specified the types of generating equipment involved in covering consumer demand. And this was justified, because when evaluating the balance reliability indicators of the entire set of randomly generated states of generating power and load, less than a percent of the states are scarce. Only in these states is the generating power fully utilized. In deficiency-free conditions, of which more than $99 \%$, the generating capacity exceeds the load. These states do not affect the indicators of balance reliability and in them the generating power can be redistributed between different types of generating equipment (hydroelectric power stations, thermal power plants, nuclear power plants, renewable energy sources) from the standpoint of ensuring a power balance.

Taking into account the participation of hydroelectric power plants in covering consumer demand in deficitfree conditions can only be carried out by separately forming the functions for reducing capacities caused by equipment outages in unscheduled (emergency) repairs, for thermal, including nuclear power plants and for hydroelectric power plants for seasonal (annual) flow control. Moreover, studies show that renewable energy can be included in the first group. Methodological approaches for assessing each state generated by power generation at HPPs and TPPs should also be transformed. Considering that the redistribution of power between hydropower plants and thermal power plants can be carried out only in deficit-free conditions and in no way affects for indicators of balance reliability, the rule of maximum load of thermal and nuclear power plants can be applied. At the same time, the algorithm for evaluating indicators of balance reliability is constructed in such a way that the loading of the hydroelectric power station from one randomly generated deficient state to another changes. The process of change is dynamic, in which the end result is the achievement, if possible, of the planned indicators of electricity production for all time intervals for which information is available on the power supply of the hydropower plant (season, year).

The task of flux distribution in the models for evaluating indicators of balance reliability is called the problem of distribution of power shortages (DPS). As the objective function, the functional was used to maximize the load supply or minimize the power shortage $[2,3]$ :

$$
\sum_{j=1}^{n} c_{j}^{H}\left(\bar{P}_{j}^{H}-P_{j}^{H}\right) \rightarrow \min ,
$$

Accounting for the energy supply of hydroelectric power plants slightly changes this target function, due to the introduction of two terms that characterize the loading of thermal (including nuclear) stations and hydroelectric power stations:

$$
\sum_{j=1}^{n} c_{j}^{H}\left(\bar{P}_{j}^{H}-P_{j}^{H}\right)+c_{j}^{2 m}\left(\bar{P}_{j}^{2 m}-P_{j}^{2 m}\right)+c_{j}^{22}\left(\bar{P}_{j}^{22}-P_{j}^{22}\right) \rightarrow m i n,
$$

where $P_{j}^{H}, \bar{P}_{j}^{H}, P_{j}^{2 m}, \bar{P}_{j}^{2 m}, P_{j}^{22}, \bar{P}_{j}^{22}$ - accordingly, covered demand and load demand capacity, used and available generating capacities of heat and hydroelectric power plants of the $\mathrm{j}$-th territorial zone; $c_{j}^{H}$-the load security factor is taken equal to unity; $c_{j}^{2 m}, c_{j}^{22}-$ coefficients reflecting the 
need for loading in deficient states of thermal and nuclear plants $\left(P_{j}^{2 m}\right)$ and hydropower plants $\left(P_{j}^{22}\right)$.

The constraints in these expressions are the observance of power balances, as well as restrictions on the load capacities and generating capacities as applied to all $\mathrm{j}$-th territorial zones [2]. The introduction of two additional terms (2) into the objective function (1) is caused by the need to redistribute the load power between thermal (including nuclear) power plants and hydroelectric power stations in non-deficient states. In order to exclude the influence of the introduced terms on the power deficit in the EPS, the magnitudes of the coefficients for these terms $\left(c_{j}^{2 m}\right.$ and $\left.c_{j}^{22}\right)$ much less (100 times or more) coefficient $c_{j}^{H}$ are accepted for the main term of the functional.

When randomly simulating the states of generating power for each time interval with a given production of electricity at hydroelectric power stations, the coefficients $c_{j}^{2 m}$ and $c_{j}^{22}$ from one state to another are not constant. Their values depend on how it is necessary to redistribute the generating capacity between thermal power plants and hydroelectric power stations in each $\mathrm{j}$ th territorial zone UES of Russia in non-deficient states, so that at the end of the simulation in the considered time interval we can get as close as possible but not exceed the production volume set on it electricity at hydroelectric power station.

\section{Methodological principles for taking into account restrictions on the production of electricity at hydroelectric power stations when substantiating power reserves}

It should be noted that the methodology for substantiating the NRP to compensate for the withdrawal of generating equipment to unscheduled (emergency) repairs (operational reserve as amended by the 2003 guidelines) remains unchanged. In modern conditions, unfortunately, there are no scientifically substantiated provisions on the application of decision-making criteria to ensure a particular level of reliability. Here you can focus on either normative indicators countries of Western Europe (LOLH $=3-8$ hours / day), or North America (LOLE $=0.1$ times a year), or the domestic standard for territorial zones $[1,3,6]\left(J_{\text {д }}=0.004\right)$.

Important for all indicators of balance reliability listed is approximately the same methodological basis for their preparation and completely different information component, especially in terms of accounting for power consumption modes [2]. The European standard is focused on the accounting of hourly electricity consumption schedules for all 8760 hours of the year, the North American provides for accounting for the load only the maximum hour of the day in year (365 values). Domestic - focused on accounting for only one hourly average daily schedule for the month of December, assuming it is valid for all working days of the year. Comparison of these indicators, from the point of view of their influence on the justification of funds reservation, the event is quite complicated. In [2], for certain conditions, such studies were carried out that showed an acceptable coincidence of the results for substantiating the value of the operational component of the NRP.

The use separate modeling of random states at HPPs and TPPs with NPPs when assessing balance reliability indicators makes it possible to determine the generating capacities required to provide the load separately for these types of stations. This opens up the possibility of determining the necessary addition to the NRP value, caused by the insufficient energy supply of hydroelectric power stations in dry years. For this, it is necessary to carry out two calculations of determining the operational reserve of capacity, which is an integral part of NRP, with the forecasted amount of electricity production at hydroelectric power stations and for a dry year. In both calculations, the value of the operational power reserve remains unchanged, but due to a change in the energy supply of the hydroelectric power station, the redistribution of generating capacities involved in covering the load between hydroelectric power station and thermal power plant with nuclear power plants will occur. The difference in the redistribution will be an additional to operational, and therefore to the NRP. The most difficult when using this approach is uncertainty information on the power supply of hydropower plants.

\section{Analysis of information on the energy supply hydroelectric power plants UES of Russia, presented in Design and Development Program UES}

When planning the balances of electricity and capacity in the work of the S\&D UES, the volume of electric power production at the hydroelectric power stations of the territorial zones is given for the most probable scenario of water supply. For Siberia and the Far East, where the share of electricity production at hydropower plants is significant (from 35\% and higher), starting in 2012, the electricity balance is also given for a dry year. It should be emphasized that at the level of regional energy systems there is no such forecast. This once again indicates the complexity of the task content when using the model design scheme UES of Russia with fragmentation into territorial zones.

In the table 1 shows the actual and forecast values of electricity production at hydroelectric power stations in Siberia (the most probable for a dry year), performed with different time periods up to 7 years. Values are for 7 years (column 1). For six of the seven years of the forecast period (columns 4 through 9), the difference in forecasts between the most probable and dry years is from 10.6 to $14.4 \%$. At the same time, when planning for the coming year (the 10th column), the forecast values coincide (except for 2014). There is no explanation for this phenomenon. It should be noted that the forecast for the coming year does not affect the conduct of CSC. 
Table 1 Actual and forecasted values of electricity production at hydroelectric power stations of Siberia in million kWh (from the work of the S\&D UES for the seven-year period 2010-2016 ... .2019-2025)

\begin{tabular}{|c|c|c|c|c|c|c|c|c|c|}
\hline \multirow{2}{*}{ Year } & \multirow{2}{*}{$\begin{array}{c}\text { Forecast } \\
\text { Characteristic }\end{array}$} & \multirow{2}{*}{ Actual } & \multicolumn{7}{|c|}{ The forecast lead time for the year given in the 1 st column } \\
\hline & & & 7 years & 6 years & 5 years & 4 years & 3 years & 2 years & 1 year \\
\hline 1 & 2 & 3 & 4 & 5 & 6 & 7 & 8 & 9 & 10 \\
\hline 2014 & $\begin{array}{l}\text { likely } \\
\text { low water }\end{array}$ & 94135,4 & no forecast & no forecast & $\begin{array}{l}108800,0 \\
\text { no info }\end{array}$ & $\begin{array}{l}105420,0 \\
\text { no info }\end{array}$ & $\begin{array}{c}102720,0 \\
91820,0\end{array}$ & $\begin{array}{c}102310,0 \\
91070,0\end{array}$ & $\begin{array}{c}103050,0 \\
89300,0\end{array}$ \\
\hline 2015 & \begin{tabular}{|l|} 
likely \\
low water
\end{tabular} & 88274,0 & no forecast & $\begin{array}{l}108800,0 \\
\text { нет инф. }\end{array}$ & $\begin{array}{l}106250,0 \\
\text { нет инф. }\end{array}$ & $\begin{array}{c}107380,0 \\
95570,0\end{array}$ & $\begin{array}{c}107610,0 \\
95560,0\end{array}$ & $\begin{array}{c}107350,0 \\
91880,0\end{array}$ & $\begin{array}{l}94696,0 \\
94696,0\end{array}$ \\
\hline 2016 & $\begin{array}{l}\text { likely } \\
\text { low water }\end{array}$ & 99845,1 & $\begin{array}{l}108800,0 \\
\text { no info }\end{array}$ & $\begin{array}{l}106960,0 \\
\text { no info }\end{array}$ & & $\begin{array}{c}107610,0 \\
95560,0\end{array}$ & $\begin{array}{c}108120,0 \\
92540,0\end{array}$ & $\begin{array}{c}108118,0 \\
92537,0\end{array}$ & $\begin{array}{l}92690,0 \\
92690,0\end{array}$ \\
\hline 2017 & $\begin{array}{l}\text { likely } \\
\text { low water }\end{array}$ & 93943,2 & $\begin{array}{l}107190,0 \\
\text { no info }\end{array}$ & $\begin{array}{c}107380,0 \\
95570,0\end{array}$ & $\begin{array}{c}107610,0 \\
95560,0\end{array}$ & $\begin{array}{c}108120,0 \\
92540,0\end{array}$ & $\begin{array}{c}108118,0 \\
92537,0\end{array}$ & $\begin{array}{c}107377,0 \\
95673,0\end{array}$ & $\begin{array}{l}93556,0 \\
93556,0\end{array}$ \\
\hline 2018 & $\begin{array}{l}\text { likely } \\
\text { low water }\end{array}$ & 101864,3 & $\begin{array}{c}107380,0 \\
95570,0\end{array}$ & $\begin{array}{c}107610,0 \\
95560,0\end{array}$ & $\begin{array}{c}108120,0 \\
92540,0\end{array}$ & $\begin{array}{c}108118,0 \\
92537,0\end{array}$ & $\begin{array}{c}107377,0 \\
95673,0\end{array}$ & $\begin{array}{c}107377,0 \\
93556,0\end{array}$ & $\begin{array}{l}89550,0 \\
89550,0\end{array}$ \\
\hline 2019 & $\begin{array}{l}\text { likely } \\
\text { low water }\end{array}$ & - & $\begin{array}{c}107610,0 \\
95560,0\end{array}$ & $\begin{array}{c}108120,0 \\
92540,0\end{array}$ & $\begin{array}{c}108118,0 \\
92537,0\end{array}$ & $\begin{array}{c}107377,0 \\
95673,0\end{array}$ & $\begin{array}{c}107377,0 \\
95673,0\end{array}$ & $\begin{array}{c}107377,0 \\
95673,0\end{array}$ & $\begin{array}{l}91080,0 \\
91080,0\end{array}$ \\
\hline 2020 & $\begin{array}{l}\text { likely } \\
\text { low water }\end{array}$ & - & $\begin{array}{c}108120,0 \\
92540,0\end{array}$ & $\begin{array}{c}108118,0 \\
92537,0\end{array}$ & $\begin{array}{c}107377,0 \\
95673,0\end{array}$ & $\begin{array}{c}107377,0 \\
95673,0\end{array}$ & $\begin{array}{c}107377,0 \\
95673,0\end{array}$ & $\begin{array}{c}107377,0 \\
95673,0\end{array}$ & no forecast \\
\hline
\end{tabular}

Noteworthy is the significant excess of the predicted values of the likely production of electricity at hydroelectric power plants (columns 4 through 9) of the actual values (column 3). For a dry year, they, as one would expect, are lower than the actual production of electricity (except for 2015), but insignificantly.

In order to take into account a possible reduction in the production of electricity at hydroelectric power plants in dry years in the task of substantiating NRP, in our opinion, it is necessary to use retrospective information on the actual production of electricity and relate forecasts for dry years to it. The average deviations of the predicted values of electricity production in dry years in accordance with the retrospective information of the table. 1 do not exceed $7.9 \%$ of actual values.

\section{A critical analysis of regulatory acts CSC in terms of the rationale for reserve capacity}

In accordance with Regulation No. 431 referred to in the above, power reserve coefficients in price zones are determined by the sum of the planned reservation coefficient, the predicted capacity underutilization coefficient, and the coefficient taking into account power export relative to the predicted combined maximum load increased by the coefficient of influence of the temperature factor. The value predicted underutilization of capacity, which depends on the average statistical value of unplanned power reductions, is taken into account when substantiating the planned redundancy ratio (17\%) in 2003 guidelines. Thus, it can be stated that when determining the redundancy coefficient in Regulation No. 431, the same indicator is taken into account twice.

The methodology for determining the operational reserve, which is an integral part of the NRP, involves taking into account the temperature factor. CSC procedure also provides for the consideration of this factor. Thus, a double account of the same factor is also observed here. In CSC procedure, this leads to an increase in demand for capacity of more than $4 \%$. The determination of the operational reserve of power

without taking into account the temperature factor leads to a decrease in NRP by approximately the same amount (from 3 to 5\%) [3], as well as an increase in demand for power. This leads to a decrease in the reserve ratio from $0.17(17 \%)$ to $0.12-0.14$.

\section{Practical results of accounting for the limited power supply of hydroelectric power stations}

Obtaining practical results on accounting for the power supply of hydropower plants was associated with the modernization of existing software ("Orion-M" [2]), including for additional information content. The content, in addition to the power supply of hydroelectric power plants, is also associated with a number of features of the assessment indicators of balance reliability used in domestic practice. This primarily relates to the description of the power consumption mode. It was noted above that in domestic practice, in determining indicators of balance reliability, the average daily hourly load graph of the month of December is used with the possibility of taking into account random deviations of the load caused by the temperature factor. It is clear that such a representation of the load can in no way be consistent with the indicators of electric energy consumption planned in the work of development scheme and program UPS. To eliminate this factor, some correction factors are introduced in the methodology. It should be emphasized that this is done not because of the impossibility of taking into account the existing or predicted modes of power consumption in the software for determining indicators of balance reliability and backup tools, but because of the lack of information available to researchers. This also applies to the energy supply of hydroelectric power stations in terms of time intervals at the level of hours, days, months.

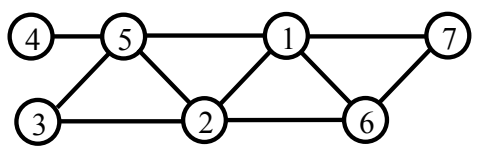

Fig. 1 - Model of the design scheme UES of Russia:

1 -Ural; 2 - Middle Volga; 3 - South; 4 - Northwest; 5 - Centre; 6 Kazakhstan; 7 - Siberia.
The rationale for the operational reserve of capacity of the territorial zones of the UPS of Russia was carried out at the level of 2022. The 
Table 2 Power and electricity balances UES of Russia for 2022 in context UES and some calculated indicators

\begin{tabular}{|c|c|c|c|c|c|c|c|}
\hline \multirow[b]{2}{*}{ Indicators } & \multicolumn{6}{|c|}{ European part of UES of Russia } & \multirow[b]{2}{*}{ Siberia } \\
\hline & Ural & Middle Volga & South & Northwest & Centre & $\begin{array}{l}\text { Total for } \\
\text { UES }\end{array}$ & \\
\hline \multicolumn{8}{|c|}{ From the power balance of work of development scheme and program UPS, MW } \\
\hline DEMAND & & & & & & & \\
\hline Combined maximum load & 37390 & 17096 & 16831 & 15151 & 39266 & 125734 & 30126 \\
\hline Power export & 290 & 10 & 350 & 1910 & & 2560 & \\
\hline \multirow{2}{*}{ Standard reserve of power, MW } & 6840 & 2351 & \multirow{2}{*}{$12,7 \%$} & 3206 & \multirow{2}{*}{$\left.6\right|_{17,42 \%} 6840$} & 21375 & 3615 \\
\hline & $18,30 \%$ & $13,74 \%$ & & 21,16 & & $17,00 \%$ & $12,00 \%$ \\
\hline TOTAL power demand & 44520 & 19457 & 19319 & 20267 & 46106 & 149669 & 34041 \\
\hline COATING & & & & & & & \\
\hline $\begin{array}{l}\text { Installed capacity, total } \\
\text { including HPP }\end{array}$ & $\begin{array}{r}53610 \\
1872\end{array}$ & $\begin{array}{r}27997 \\
7008\end{array}$ & $\begin{array}{r}24740 \\
6342\end{array}$ & $\begin{array}{r}25956 \\
3005\end{array}$ & $\begin{array}{r}55616 \\
2639\end{array}$ & $\begin{array}{r}187919 \\
20866\end{array}$ & $\begin{array}{l}52029 \\
25291\end{array}$ \\
\hline Limitations and locked power & 2494 & 2119 & 2337 & 2751 & 958 & 10568 & 12404 \\
\hline TOTAL coverage of demand & 51116 & 25878 & 22403 & 23207 & 54658 & 177261 & 39625 \\
\hline Excess $(+) /$ deficiency $(-)$ & 6596 & 6421 & 3084 & 2940 & 8552 & 27592 & 5584 \\
\hline \multicolumn{8}{|c|}{ From the balance of work of development scheme and program UPS, GWh } \\
\hline Electricity production, total & 265218 & 105638 & 99857 & 111041 & 242296 & 824050 & 209729 \\
\hline including HPP & 4966 & 20310 & 21730 & 12629 & 4745 & 64380 & 107377 \\
\hline low water & - & - & $-\quad$ & - & - & & 95673 \\
\hline \multicolumn{8}{|c|}{ Estimated figures, MW } \\
\hline \multirow{2}{*}{$\begin{array}{l}\text { Power used to cover the load, total, MW } \\
\text { including HPP }\end{array}$} & 42234 & 17574 & 18385 & 16805 & 43031 & 138029 & 33501 \\
\hline & 1938 & 6983 & 6365 & 1800 & 2407 & 19493 & 20801 \\
\hline \multirow[t]{2}{*}{ Operational reserve of power, MW / } & 4844 & 478 & 1554 & 1654 & 3765 & 12295 & 3375 \\
\hline & 12,96 & 2,8 & 9,23 & 10,92 & 9,59 & 9,78 & 11,2 \\
\hline
\end{tabular}

information content of task was carried out from the work of the S\&D UES of Russia for 2016-2022. The design scheme (Fig. 1), the composition of the generating equipment, the power consumption regimes for December days, probabilistically determined data on random load deviations, equipment outages for unscheduled repairs were obtained during work and are partially presented ${ }^{c}$ in the monograph [2].

In the table 2 shows the power balance for 2022 , which indicates the presence of significant excess capacity: in the European part of the UES, they make up $21.94 \% \quad(27592 / 125734), \quad$ in Siberia - $18.53 \%$ (5584/30126). The purpose of CSC is to select the most efficient generating units of power plants from the existing excess composition of generating equipment to cover possible consumer demand. We emphasize once again that the demand for capacity, both during the development of 2003 guidelines [1], and in Regulation No. 431, depends on the size of the NRP. In the table 2, the regulatory reserve is given in accordance with [1].

The share of electricity production at hydroelectric power stations in the European part UES of Russia is only $7.8 \%(64380 / 824050)$, in Siberia $51.2 \%$ (107377/209729). This can explain the introduction of an additional component to the NRP during the CSC for the price zone of Siberia, caused by possible regime restrictions of hydroelectric power plants in dry years. Given in the table 3 , the calculated information on the operational component of the NRP shows the contradictions of the NRP values used in compiling the power balances in the work of the S\&D UES of Russia according to the recommendations [1] of modern conditions, especially for Siberia. The share of the strategic and repair component in the NRP value for the

\footnotetext{
c Report on scientific and research work Justification of the normative values of the components of the full reserve of power in the context of the UES and UES of Russia as a whole when planning their development. / Syktyvkar, 2016 - 66 p. (Contract ISEandEPN Komi SC UB RAS with JSC SO UES, No. 926 dated September 22, 2016)
}

Siberian Energy System is only $0.6 \%$. This circumstance can explain the adoption of the NRM during the CSC for the price zone of Siberia is not $12 \%$, but $17 \%$, as in the European part of UES.

Table 3. Additives to the normative power reserve caused by a possible decrease in electricity production at hydroelectric power plants of the Siberian Energy System

\begin{tabular}{|l|l|l|l|}
\hline The percentage & \multicolumn{3}{|c|}{ Indicator } \\
\cline { 2 - 4 } $\begin{array}{l}\text { reduction in } \\
\text { electricity } \\
\text { production at } \\
\text { HPP }\end{array}$ & $\begin{array}{c}\text { The } \\
\text { percentage } \\
\text { reduction } \\
\text { in } \\
\text { electricity } \\
\text { production } \\
\text { at HPP }\end{array}$ & $\begin{array}{c}\text { HPP power } \\
\text { in load } \\
\text { coverage }\end{array}$ & $\begin{array}{l}\text { Additive to } \\
\text { the power } \\
\text { reserve } \\
\text { MW/ \% }\end{array}$ \\
\hline 0 & 107377 & 20801 & $0 / 0$ \\
\hline 2.5 & 104692 & 20431 & $370 / 1.22$ \\
\hline 5.0 & 102008 & 20071 & $730 / 2.42$ \\
\hline 7.5 & 99324 & 19701 & $1100 / 3.65$ \\
\hline 10.9 & 95673 & 19196 & $1605 / 5.33$ \\
\hline 15.0 & 91270 & 18571 & $2230 / 7.4$ \\
\hline 17.27 & 88832 & 18225 & $2576 / 8.55$ \\
\hline
\end{tabular}

In the table 3 presents the results of the addition to NRP obtained as a result of applying the above procedure. It can be seen that an addition to NRP of $8.55 \%$, adopted in accordance with paragraph 107 of the Wholesale Market Rules ${ }^{\mathrm{d}}$, is possible for the case where

\footnotetext{
${ }^{d}$ Decree of the Government of the Russian Federation No. 1172 dated December 27, 2010 (as amended on January 19, 2018) "On the Approval of the Rules for the Wholesale Market of Electric Energy and Power and on Amending Certain Acts of the Government of the Russian Federation on the Organization of the Operation of the Wholesale Market of Electric Energy and Power".
} 
the difference in electricity production between the most probable and dry years is $17.27 \%$. Such a difference was not observed in any edition of work of the S\&D UES of Russia (table 1). For the year under review, she, in accordance with table 2, makes up only $10.9 \%$ (107377 and 95673 million $\mathrm{kWh})$. The decline in electricity production at hydroelectric power stations in Siberia in dry years should not exceed $7.9 \%$ (section 4). This corresponds to the addition to the operational power reserve of a maximum of 4 , but not 8.55 percent, taken during the development of CSC for 2022-2024. A decrease in the value of the addition to the planned reserve ratio from $8.55 \%$ to $4.5 \%$ will lead to a decrease in demand for capacity by more than $1800 \mathrm{MW}$.

Thus, the contradictions identified in the previous section when determining the demand for power when using the information necessary for carrying out CSC for 2022-2024 and the results presented in this section on the effect of underutilization of Siberian hydroelectric power stations in dry years in relation to 2022 lead to:

- for the price zone European part UES, to a decrease in demand for capacity of more than $5 \mathrm{GW}(3.5 \%)$, in monetary terms when extrapolating CSC 2020, to a decrease in the cost of capacity by more than 13 billion rubles;

- for the Siberia price zone, the decrease in demand for capacity is more than $1.5 \mathrm{GW}(3.5 \%)$, and if we take into account the correction coefficient $(8.55 \%)$, taking into account the limitations of hydroelectric power plants in dry years, then about $3.3 \mathrm{GW}(7.8 \%)$ or a decrease in the cost of capacity by more than 16 billion rubles.

\section{References}

1. Guidelines for designing development of energy systems. (Approved by Order of the Ministry of Energy of Russia dated June 30, 2003, No. 281). M $\therefore$ Ministry of Energy of the Russian Federation, CO 153-34.20.118-2003.

2. Chukreev Yu.Ya., Chukreev M.Yu. Models assessing balance sheet reliability indicators for managing development of electric power systems. Syktyvkar: Komi Scientific Center, Ural Branch of the Russian Academy of Sciences, 2014, 207 p.

3. Chukreev Yu.Ya. Models ensuring reliability of electric power systems. Syktyvkar: Komi Scientific Center, Ural Branch of the Russian Academy of Sciences, $1995.176 \mathrm{p}$.

4. Kovalev G.F., Lebedeva L.M. Reliability of power systems. Novosibirsk: Nauka, 2015, 224 p.

5. Billinton R., Allan R.N. Reliability Evaluation of Power Systems. Second Edition. (New York and London, Plenum Press, 1996)

6. Volkenau I.M., Zeiliger A.N., Khabachev L.D. Economics of formation electric power systems. M $\therefore$ Energoatomizdat, 1981, 320 pp.

\footnotetext{
e Website of SO UES JSC Competitive power take-off; monitor.so-ups.ru.
} 